\title{
RESEARCH OF ENERGY CAPACITY OF STRUCTURAL COMMINUTION IN DEEP LOOSING OF SANDY AND LOAMY SOIL
}

\author{
Yury Mazhayskiy $^{1}$, Anatoly Rokochynskiy², Olexander Lukianchuk ${ }^{2}$, Pavlo Volk ${ }^{2}$, Vasyl Turcheniuk ${ }^{2}$, \\ Olga Chernikova ${ }^{3}$
}

${ }^{1}$ All-Russian Research Institute of Hydrotechnics and Melioration named after A.N. Kostyakova, Russia; ${ }^{2}$ National University of Water and Environmental Engineering, Russia; ${ }^{3}$ Academy of Law Management of the Federal Penal Service of Russia, Russia director@mntc.pro, a.m.rokochinskiy@nuwm.edu.ua, o.p.lukyanchuk@nuwm.edu.ua, p.p.volk@nuwm.edu.ua, v.o.turchenuk@nuwm.edu.ua,chernikova_olga@inbox.ru

\begin{abstract}
In changing climatic conditions, the deep continuous loosening of soil developed by us can be the most effective alternative measure for expensive reconstruction of existing reclamation systems and, at the same time, an effective adaptive means for the accumulation of free soil moisture. The accumulation efficiency depends on the structure of the loosened soil. Due to the large amount of work with continuous deep loosening and the need to significantly change the structure of the soil, this process is quite energy consuming. Having determined the energy consumption for comminution the soil and comparing it with all the energy that is spent by the subsoiler on loosening the soil mass, we obtain its efficiency, the analysis of which, in turn, will allow us to evaluate the effectiveness of possible ways to improve the technological and economic performance indicators. Experimental research was planned and carried out on the basis of the methods of full factorial experiment, probability theory and mathematical statistics. The value of the proportionality coefficient of the Bond comminution hypothesis was experimentally established, which makes it possible to determine the energy saturation of technical means for loosening a certain soil mass. The obtained values were used to calculate the required minimum capacity of technical means for deep continuous loosening and basic tillage. It has been established that the required capacity of technical means for deep loosening is approximately 2 times less for sandy soil than for loamy soil. So, with a total working width of $2 \mathrm{~m}$, a working speed of $2 \mathrm{~m} \cdot \mathrm{s}^{-1}$ for deep loosening (by $0.75 \mathrm{~m}$ ) and $4 \mathrm{~m} \cdot \mathrm{s}^{-1}$ for the basic tillage (by $0.25 \mathrm{~m}$ ), it is necessary to have the power of $170-240 \mathrm{~kW}$ of technical equipment for sandy soil and 390-440 for loamy soil.
\end{abstract}

Keywords: loosening, soil, comminution, energy.

\section{Introduction}

In changeable climatic conditions, the deep continuous loosening of mineral soil developed by us can be the most effective alternative measure for expensive reconstruction of existing reclamation systems, and, at the same time, an effective adaptive means for the accumulation of free soil moisture [1-3]. Such an event may be particularly relevant with limited funding for the reconstruction of land reclamation systems.

In order to eliminate the disadvantages of traditional means of deep loosening and take into account the necessary technological changes, new in principle of operation, multi-tiered working bodies were developed and proposed (Fig. 1) [3; 4]. In contrast to the generally accepted working bodies of subsoilers, low-energy-consuming methods of influencing the soil environment are used here.

The accumulation efficiency depends on the structure of the loosened soil. Due to the significant amount of work with continuous deep loosening and the need for significant comminution of the soil massif, this process is quite energy-consuming [5-8].

The process of soil comminution can be viewed from different perspectives. Classical mechanics provides the following: external forces cause the accumulation of internal energy of elastic deformations, stresses in the soil body increase until the tensile strength is exceeded as a result of the concentration of stresses in some local defect. Then the crack begins to develop, accompanied by a redistribution of the energy of elastic deformations, part of which is converted into the energy of the newly formed surfaces. This part of the energy is the useful energy of the comminution. The rest of the energy is for elastic compression deformations and is dissipated in the form of heat and other types of energy.

A feature of the physics of the process is the wave nature of the deformation and comminution process. In such a process, there is a radial divergence of the motion of particles with the transformation of local compression into tension and movable deformations of the entire volume of the soil element. In 
addition, the features of soil rheology are used, namely, the dependence of the tensile strength of the soil on the rate of load application [9].

In the literature, there are not recognized physically adequate and scientifically grounded theories that allow to analytically determine the degree of soil comminution during various types of tillage, depending on the parameters of the soil and working bodies. There are only a few attempts to indirectly determine soil comminution. So, V.V. Katsigin theoretically determined the effect of the speed of tillage machines on the intensity of soil comminution, using the hypothesis of I. Pokrovskiy, who believed that the destruction of material occurs at a certain amount of energy absorbed by a unit volume of matter. V.V. Katsigin argues that the comminution of the layer depends not so much on the magnitude of the stress as on the difference in the stress state of neighbouring soil elements, that is, on the stress gradient and on the nature of the stress state of the entire soil layer [9].

As it was established above, when the working body moves in the soil, a stressed zone is formed in front of it. The stress gradient in this zone depends on the intensity of absorption of the energy flux, transmitted in the wave process, by the soil. Obviously, the separation of the layer into separate fractions will be the higher, the more energy is absorbed in the shear zone (shearing). Therefore, the smaller the volume of the deformed layer, the greater the effect of soil deformation can be expected.

Real soil is permeated with a large number of different dislocations (defects): cracks, voids, foreign inclusions, etc. As the stress state of the soil increases so the separate fractures occur under the action of the applied load around some defects, for example, cracks as stress concentrators. This occurs primarily in places where the stress is greater than the strength of inter-aggregate bonds. At these moments, avalanche-like destruction of the monolith formation occurs, and it crumbles into separate aggregates.

The intensity of soil comminution with increasing speed first increases sharply, and then this growth practically stops. This is due to the scale factor, that is, the dependence of strength on the size of the destroyed body. The process of coarse comminution, as already mentioned above, can be represented, basically, as the development of existing defects in the structure. With the transition to comminution small fractions, defects become rarer in them, and the conglomerates become more and more durable. The energy consumption for tillage begins to grow rapidly with the approach of working speeds to the speed of propagation of plastic deformations, and the degree of comminution increases insignificantly. Therefore, there are physical limits of working speeds, exceeding which is irrational, for each type of tillage machines.

The classical laws of comminution relate the energy (work) that needs to be spent on the comminution (destruction) process of a material with the dimensions of the finished product.

In order to determine the energy required for the soil comminution, several hypotheses have been developed: the surfaces hypothesis of P. Rittinger indicates the proportionality of the energy of the newly formed surface; the Kirpichev-Kick volume hypothesis - about the proportionality of energy to the volumes or masses of the shredded bodies; the combined hypothesis of P. Rebinder - about the proportionality of the comminution energy to the surfaces formed in the volume of the crushed body [9].

All comminution laws can be presented in the form of a generalized form proposed by R. Charles

$$
d E=k \frac{d x}{x^{n}},
$$

where $d E$ - energy required to reduce a piece of rock with $x$ size by $d x$ value;

$k$ - proportionality coefficient;

$n$ - exponent depending on the size of the parts (constant).

However, the most practical one is the comminution hypothesis, which was proposed by Bond, in the form of the obtained regularity

$$
E=k_{n}\left(\frac{1}{\sqrt{d_{c e p}}}-\frac{1}{\sqrt{D_{c e p}}}\right) M,
$$

where $k_{n}$ - proportionality coefficient, $\mathrm{H} \cdot \mathrm{m}^{1.5} \cdot \mathrm{kg}^{-1}$ 
$d_{c e p}$ and $D_{c e p}-$ average sizes of the initial and crushed product, $\mathrm{m}$;

$M$ - mass of the material that is crushed, $\mathrm{kg}$.

The Bond equation can be obtained by integrating Charles' generalizing formula (1) with $n=1.5$. (2).

The relative linear dimensions $d_{\text {сер }}$ и $D_{\text {сер }}$ can be defined as geometric or arithmetic mean values.

The objective of this work is to ultimately establish ways to reduce the energy consumption of the work of subsoilers.

Having determined the energy consumption for the soil comminution and comparing it with all the energy that is spent by the subsoiler for loosening the soil mass, we obtain its efficiency, the analysis of which, in turn, will allow us to evaluate the effectiveness of possible ways to improve the technological and economic performance indicators.

The hypothesis proposed by Bond takes into account both the energy for the formation of new surfaces and the energy for deformation of the body. Determining the dimensions of the input and output product, as well as their mass, is not difficult. The biggest problem in using this relation is to establish the value of the proportionality coefficient. For this, the experimental research was carried out.

\section{Materials and methods}

The experimental research is planned and carried out on the basis of the methods of full factorial experiment, probability theory and mathematical statistics.

The tasks that were solved during the experiment: determination of the dependence of the degree of comminution on the type of soil (by the average size of lumps), determination of the comminution energy of the soil sample under research.

To carry out the experiment, we used a soil sample in the form of a cube with a side equal to $D_{k}=30 \mathrm{~cm}$, since this corresponds to the possible size of the loosening layer by a separate working body of the longline subsoiler $[10 ; 11]$.

The volume of the selected cube is

$$
V_{k}=D_{k}{ }^{3}=0.33=0.027 \mathrm{~m}^{3} \text {. }
$$

The experiment was carried out for sandy and loamy soil types.

The factors of the experiment were the height of the fall and the type of soil. The experiment was carried out at three levels with a triple repetition.

The characteristics of the soil are shown in Table 1.

Physical and mechanical properties of the researched soil

Table 1

\begin{tabular}{|l|c|c|c|}
\hline \multicolumn{1}{|c|}{ Soil type (category) } & $\begin{array}{c}\text { Light sandy soil } \\
\text { (I) }\end{array}$ & $\begin{array}{c}\text { Medium sandy } \\
\text { soil (II) }\end{array}$ & $\begin{array}{c}\text { Light loamy soil } \\
\text { (II) }\end{array}$ \\
\hline Relative humidity, \% & 11.1 & 13.0 & 14.3 \\
\hline The number of hits of density meter & 3 & 5 & 8 \\
\hline Density, $\mathrm{t} / \mathrm{m} 3$ & 1.85 & 2.00 & 2.15 \\
\hline Plasticity number & 2.1 & 4.4 & 9.1 \\
\hline Consistency & 0.75 & 0.2 & -0.2 \\
\hline Internal friction force, MPa & 0.002 & 0.015 & 0.06 \\
\hline Internal friction angle, degrees & 18 & 26 & 25 \\
\hline
\end{tabular}

\section{Results and discussion}

The comminution process was simulated by providing a soil sample with a certain potential energy. To do this, this sample was raised to a certain height and released. After interaction with the day surface, the soil sample was crushed (Fig. 1).

The required height was determined taking into account the speed at the end of the fall, equal to the speed of movement of the working body $v$ in the range of $3.1 \ldots 5.4 \mathrm{~m} \cdot \mathrm{s}^{-1}$ according to the free fall formula 


$$
h=\frac{v^{2}}{2 g} .
$$

After comminution the soil sample, the obtained fractions were sorted. The following fraction intervals were selected: $>15 \mathrm{~cm} ; 10 \ldots 15 \mathrm{~cm} ; 5 \ldots 10 \mathrm{~cm} ; 3 \ldots 5 \mathrm{~cm} ; 1.5 \ldots 3 \mathrm{~cm} ;<1.5 \mathrm{~cm}$.

Fractions of $>15 \mathrm{~cm} ; 10 \ldots 15 \mathrm{~cm} ; 5 \ldots 10 \mathrm{~cm} ; 3 \ldots 5 \mathrm{~cm}$ were sorted manually, and fractions of $1.5 \ldots 3 \mathrm{~cm} ;<1.5 \mathrm{~cm}$ - using a sieve with apertures of $1.5 \times 1.5 \mathrm{~cm}$, that is, everything that passed through the sieve belonged to the fraction of $<1.5 \mathrm{~cm}$, - and what remained on the sieve belonged to the fraction of $1.5 \ldots 3 \mathrm{~cm}$.

a)
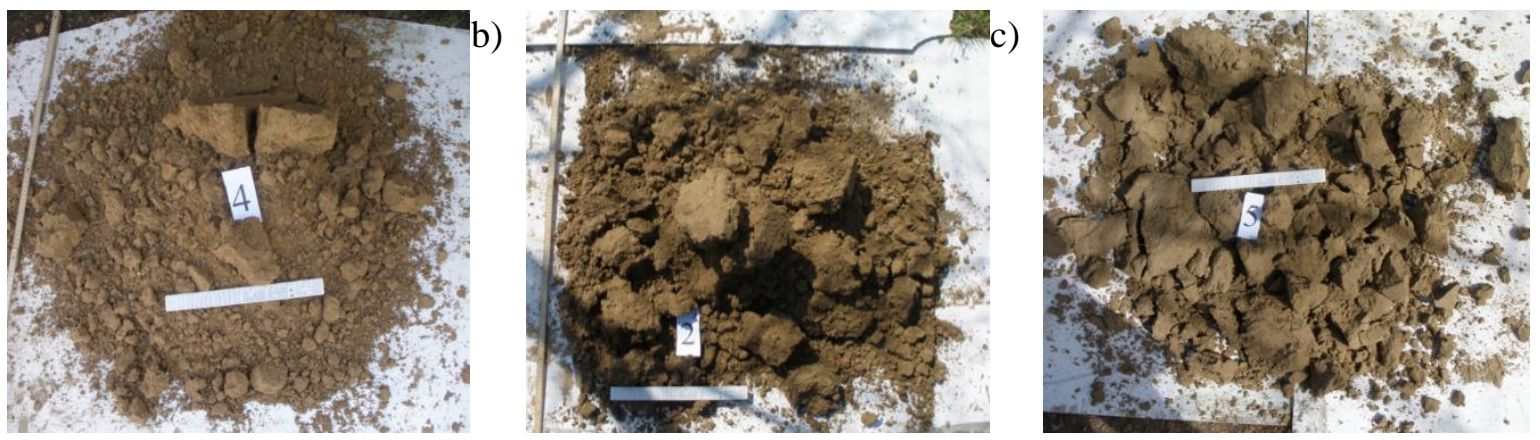

Fig. 1. Soil comminution in individual experiments after falling from a height of $\boldsymbol{h}=\mathbf{1 . 1} \mathbf{m}$ :

a - light sandy soil; b - medium sandy soil; $\mathrm{c}$ - light loamy soil

After separation into fractions, each fraction was weighed for each type of soil and different heights (Table 2).

Table 2

\section{Experiment results}

\begin{tabular}{|c|c|c|c|c|c|c|c|c|}
\hline \multirow[t]{2}{*}{ Soil type } & \multirow{2}{*}{$\begin{array}{l}\text { Sample } \\
\text { mass, kg }\end{array}$} & \multirow[t]{2}{*}{$h, \mathbf{g}$} & $\begin{array}{l}>15 \\
\mathrm{~cm}\end{array}$ & $\begin{array}{c}10 . . .15 \\
\text { cm }\end{array}$ & $\begin{array}{c}5 \ldots 10 \\
\mathrm{~cm}\end{array}$ & $\begin{array}{c}3 . . .5 \\
\mathrm{~cm}\end{array}$ & $\begin{array}{c}1.5 . . .3 \\
\text { cm }\end{array}$ & $\begin{array}{l}<1.5 \\
\mathrm{~cm}\end{array}$ \\
\hline & & & \multicolumn{6}{|c|}{ Averaged percentage of fractions, $\%$} \\
\hline Light sandy soil & 49 & \multirow{3}{*}{0.5} & 26 & 0 & 11 & 10 & 16 & 37 \\
\hline Medium sandy soil & 54 & & 36 & 21 & 13 & 9 & 6 & 16 \\
\hline Light loamy soil & 58 & & 69 & 4 & 6 & 5 & 6 & 11 \\
\hline Light sandy soil & 49 & \multirow{3}{*}{1.0} & 21 & 5 & 7 & 7 & 9 & 51 \\
\hline Medium sandy soil & 54 & & 26 & 20 & 10 & 14 & 6 & 24 \\
\hline Light loamy soil & 58 & & 36 & 19 & 18 & 6 & 4 & 16 \\
\hline Light sandy soil & 49 & \multirow{3}{*}{1.5} & 10 & 10 & 10 & 12 & 12 & 45 \\
\hline Medium sandy soil & 54 & & 24 & 10 & 14 & 14 & 18 & 21 \\
\hline Light loamy soil & 58 & & 32 & 17 & 13 & 9 & 10 & 19 \\
\hline
\end{tabular}

The relative average error in the quantitative index of fractions was $6.51 \%$ for light sandy loam, $5.54 \%$ for medium sandy loam, and $4.58 \%$ for light loam.

The average size of the fraction was determined by the equation

$$
d_{c p}=\sum_{j=1}^{n} d_{j} \cdot Q_{j} / Q_{n},
$$

where $d_{c e p}-$ average size of the fraction, $\mathrm{m}$;

$Q_{j}$ - mass of lumps in the $j$-th fraction, $\mathrm{kg}$;

$Q_{n}$ - total mass of the cube of the researched soil, $\mathrm{kg}$.

Knowing the height of the rise of the sample, by means of mathematical transformations, the potential energy, which was expended in comminution the soil sample, was determined.

The degree of comminution $i$ was determined by the ratio of the average sizes of fractions before and after comminution 


$$
i=\frac{D_{c e p}}{d_{c e p}} .
$$

The average size before comminution $D_{c e p}$ is equal to the side of the cube of the researched soil, that is, $D_{\text {cep }}=0.3 \mathrm{~m}$.

The proportionality coefficient, according to the hypothesis of soil comminution proposed by Bond, taking into account the expression for the potential energy, was determined as follows

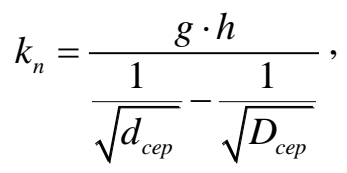

where $h$-height of the soil fall, m;

$d_{c e p}$ and $D_{c e p}-$ average sizes of the original and comminution product, $\mathrm{g}$.

The proportionality coefficient was determined for each experiment and then averaged over the type of soil. Having obtained these data, using the Bond formula, we determined the energy $E_{n}$ for the soil comminution, reduced for convenience to $1 \mathrm{~m}^{3}$, with the formation of average particle sizes of 10 and $25 \mathrm{~mm}$, as the most desirable in the structure of loosened soil, respectively, arable and lower layers (see Table 3).

The calculation of the $d_{c e p}$ value is given in Table 3 .

\begin{tabular}{|c|c|c|c|c|c|c|c|c|}
\hline \multirow[t]{2}{*}{ Soil type } & \multirow[t]{2}{*}{$\begin{array}{c}\text { Density, } \\
\mathbf{t} \cdot \mathbf{m}^{-3}\end{array}$} & \multirow[t]{2}{*}{$h, \mathbf{m}$} & \multirow[t]{2}{*}{$d_{c e p}, \mathbf{m}$} & \multirow[t]{2}{*}{$i$} & \multirow[t]{2}{*}{$\begin{array}{c}k_{\mathrm{n}}, \\
\mathrm{H} \cdot \mathrm{m}^{1.5} \cdot \mathrm{kg}^{-1}\end{array}$} & \multirow[t]{2}{*}{$\begin{array}{c}\text { Average } \\
\text { value of } k_{\mathrm{n}}, \\
\mathrm{H} \cdot \mathrm{m}^{1.5} \cdot \mathrm{kg}^{-1}\end{array}$} & \multicolumn{2}{|c|}{$\begin{array}{c}\text { Reduced } \\
\text { comminution } \\
\text { energy, } \\
E_{n}, \mathbf{k J}\end{array}$} \\
\hline & & & & & & & $10 \mathrm{~mm}$ & $25 \mathrm{~mm}$ \\
\hline \multirow{3}{*}{$\begin{array}{l}\text { Light } \\
\text { sandy soil }\end{array}$} & \multirow{3}{*}{1.85} & 0.5 & 0.1354 & 2.22 & 5.49 & \multirow{3}{*}{5.71} & \multirow{3}{*}{95.1} & \multirow{3}{*}{56.2} \\
\hline & & 1.0 & 0.0730 & 4.11 & 5.75 & & & \\
\hline & & 1.5 & 0.0534 & 5.62 & 5.88 & & & \\
\hline \multirow{3}{*}{$\begin{array}{l}\text { Medium } \\
\text { sandy soil }\end{array}$} & \multirow{3}{*}{2.00} & 0.5 & 0.1521 & 1.97 & 6.64 & \multirow{3}{*}{6.71} & \multirow{3}{*}{120.8} & \multirow{3}{*}{71.5} \\
\hline & & 1.0 & 0.0928 & 3.23 & 6.73 & & & \\
\hline & & 1.5 & 0.0626 & 4.79 & 6.78 & & & \\
\hline \multirow{3}{*}{$\begin{array}{l}\text { Light } \\
\text { loamy soil }\end{array}$} & \multirow{3}{*}{2.15} & 0.5 & 0.1993 & 1.51 & 11.84 & \multirow{3}{*}{11.29} & \multirow{3}{*}{218.5} & \multirow{3}{*}{129.2} \\
\hline & & 1.0 & 0.1332 & 2.25 & 10.73 & & & \\
\hline & & 1.5 & 0.1023 & 2.93 & 11.31 & & & \\
\hline
\end{tabular}

Results of calculating comminution indicators

Based on the obtained values, it is possible to calculate the required minimum capacity of technical means for deep loosening and basic tillage. So, with a total working width of $2 \mathrm{~m}$, a working speed of $2 \mathrm{~m} \cdot \mathrm{s}^{-1}$ for deep loosening (by $0.75 \mathrm{~m}$ ) and $4 \mathrm{~m} \cdot \mathrm{s}^{-1}$ for the basic tillage (by $0.25 \mathrm{~m}$ ), it is necessary to have the power of 170-240 kW of technical equipment for sandy soil and 390-440 for loamy soil.

\section{Conclusions}

1. The effectiveness of the Bond's comminution hypothesis was confirmed: with an increase in the energy provided to the soil, the degree of its comminution increases: when the energy is increased by 1.7 times, the grinding increases by 2.5 times.

2. The value of the proportionality coefficient of the Bond's comminution hypothesis was experimentally established, that makes it possible to determine the energy saturation of technical means for loosening a certain soil mass: for light sandy loam, it is 5.71, for medium sandy loam6.71, for light loam - 11.29.

3. The required power of technical means for deep loosening of soil is almost 2 times less for sandy soil than for loamy soil. Conclusions can be represented using plain text or numbered using appropriate style: an average of $205 \mathrm{~kW}$ vs. $415 \mathrm{~kW}$. 


\section{References}

[1] Iglesias A., Garrote L. Adaptation strategies for agricultural water management under climate change in Europe. Agricultural Water Management, vol. 155, 2015, pp. 113-124.

[2] Kovalenko P., Rokochinskiy A., Jeznach J. etc. Evaluation of climate change in Polissie region and ways of adaptation to it. Journal of Water and Land Development, 2019, Volume 41. Issue 1. pp. 7282.

[3] Mazhayskiy Y., Rokochynskiy A., Lukianchuk O. etc. Deep loosening as effective adaptive agromeliorative practice on drained mineral soil of European polesie in variable climatic conditions. Engineering for Rural Development, 2020, 19, pp. 28-35.

[4] Laziuta M., Kabulova B., Gasanov C. Research of soil tillage by advanced design slit ripper. Agricultural Engineering. Research papers, 2016, vol. 45, No. 2. Policy, vol. 59, 2016, pp. 152-164.

[5] Berntsen R., Berre B. Fragmentation and energy efficiency in the preparation of seedbeds. In: Morrison, J.E. (Ed.). Proceedings of the 15th International Conference of the International Soil Tillage Research Organisation, ISTRO-2000, June 2000, P. Dyke, Texas Agricultural Experiment Station, Temple, Texas, USA.

[6] Odey S.O., Ovat F.A., Okon O.O. Draughts, Power Requirements and Soil Disruption of Subsoilers International Journal of Emerging Engineering Research and Technology Volume 6, Issue 9, 2018, pp. 24-38

[7] Gaffarov Kh.R. What determines the quality and energy performance of machines and implements for deep tillage? "Young Scientist". Technical science. No. 5 (109). March 2016, pp. 31-32. (In Russian)

[8] Odey S.O., Manuwa S.I. Design steps of narrow tillage tools for draught reduction and increased soil disruption - a review. Agric Eng Int: CIGR Journal, 2016, 18 (1): 91-102. (in Ukrainian)

[9] A.N. Panchenko, Dnepropetrovsk state agr. un-t. - Dnepropetrovsk. 1999. - 140 p. (in Ukrainian).

[10] Lukyanchuk O.P., Ryzhyi O.P., Ihnatiuk R.M. Design of a tiered operating unit for deep differentiated tillage. Scientific Bulletin of the National Mining University, 2017, Is. 4, pp. 43-48.

[11] Lukyanchuk O.P., Turcheniuk V.O., Prykhodko N.V. etc. Necessity and possible approaches to applying deep loosening when cultivating rice // INMATEH - Agricultural Engineering. Vol. 57, No.1/ 2019. pp. 199-207. 